\title{
Differential expression of metallothionein type-2 homologues in leaves and roots of Black pepper (Piper nigrum L)
}

\author{
Susan M. Alex, Jose Dicto, M.G. Purushothama and S. Manjula \\ Division of Plant Molecular Biology, Rajiv Gandhi Centre for Biotechnology, Thiruvananthapuram, \\ Kerala, India.
}

\begin{abstract}
Black pepper (Piper nigrum L.), member of the family Piperaceae is indigenous to India and is one of the most widely used spices in the world. In this paper we report the results of our attempts to identify a set of genes differentially expressed in the leaves of Piper nigrum, which could facilitate targeted engineering of this valuable crop. A PCR-based Suppression Subtractive Hybridization (SSH) technique was used to generate a leaf-specific subtracted cDNA library of Piper nigrum. A tester population of leaf CDNA was subtracted with a root derived driver CDNA. The efficiency of subtraction was confirmed by PCR analysis using the housekeeping gene actin. On sequence analysis, almost $30 \%$ of the clones showed homology to metallothionein type-2 gene. The predominance of metallothionein transcripts in the leaf was further confirmed using Real-Time PCR analyses and Northern blot. The possible role of metallothionein type-2 homologues in the leaf is discussed along with the feasibility of using SSH technique for identification of more number of tissue-specific genes from Piper nigrum.
\end{abstract}

Key words: Piper nigrum, suppression subtractive hybridization, metallothionein type-2, real-time PCR analysis, Northern blotting.

Received: December 3, 2007; Accepted: March 10, 2008.

Piper nigrum (Black pepper), the most acclaimed member of the family Piperaceae is a perennial climbing vine grown for its berries, which are highly priced as spice and medicine all over the world. India, especially the Southern states, accounts for a major portion of black pepper production. Recently, a very efficient micropropagation strategy through somatic embryogenesis was reported from seeds of Piper nigrum (Nair and Gupta, 2006), which could enable genetic manipulation of this crop for specific agronomic traits including abiotic and biotic stress tolerance. Often, improvement of transgenic traits in plants is achieved by using specific promoters to accomplish high tissue-specific protein production in transgenic plants. In Piper nigrum, promoters with leaf and root targeted expression would ensure that the gene product will not be present in the edible portions. Moreover, native promoters are known to mimic the expression of endogenous genes more effectively and do not appear to be greatly affected by gene silencing (Song et al., 2000). Having a resource of candidate genes and promoters would enable effective development of more acceptable transgenic varieties. Previously, our group has used SSH technique, which is a modified PCR based cDNA subtraction, to successfully generate a

Send correspondence to S. Manjula. Division of Plant Molecular Biology, Rajiv Gandhi Centre for Biotechnology, Thiruvananthapuram 695014 Kerala, India. E-mail: smanjula@ rgcb.res.in. defense gene enriched subtracted cDNA library in the resistant wild pepper (Piper colubrinum Link) (Dicto and Manjula, 2005). In the present study, Suppression Subtractive Hybridization strategy was used to identify a set of genes preferentially expressed in the leaf tissue of Piper nigrum and we report here the results of the forward subtraction using leaf as the tester and root as the driver population.

Fresh vine cuttings of Piper nigrum var Panniyur-I were procured from the Kerala Agricultural University, Vellayani, Trivandrum, Kerala, India and transferred to pots containing soil and sand mixture in 3:1 proportion. They were maintained in the greenhouse of Rajiv Gandhi Centre for Biotechnology, Trivandrum, Kerala, India. Leaves and roots were collected from 6-month-old plants. Two-three leaves from very young $\left(1^{\text {st }}\right.$ leaves $)$ to mature fully expanded $\left(5^{\text {th }}\right.$ and $\left.6^{\text {th }}\right)$ stages were pooled for the extraction of RNA and further cDNA synthesis. Root samples were collected by carefully up-rooting the plants. The tissues were surface sterilized separately in running water using detergent followed by a couple of rinses in sterile Milli $Q$ water. They were dried in filter paper and cut into $1 \mathrm{~cm}$ long pieces.

For SSH, $800 \mathrm{mg}$ of leaf and $1.2 \mathrm{~g}$ of root samples were frozen in liquid nitrogen and ground to fine powder in a mortar and pestle. Total RNA extraction was carried out using TRIzol (Invitrogen) method. Poly (A) mRNA was 
purified from the total RNA using the Poly AT-tract mRNA isolation kit (Promega Inc. Madison, USA) and Suppression Subtractive Hybridization was performed using PCRSelect cDNA Subtraction kit (Clontech, USA) as instructed by the manufacturer. Two populations of cDNA were synthesized, a tester cDNA corresponding to $2 \mu \mathrm{g}$ of mRNA was prepared from leaves and a driver cDNA was prepared from $2 \mu \mathrm{g}$ of mRNA isolated from roots. Both the cDNA populations were digested with $R s a I$ and the tester cDNA was sub-divided into two populations, and each was ligated with a different cDNA adaptor provided in the kit. Two rounds of hybridizations were performed followed by two rounds of PCR amplifications. The subtracted PCR products were checked on a $1.2 \%$ agarose $/ \mathrm{EtBr}$ gel. For analysis of subtraction efficiency, the house keeping gene, actin from Piper nigrum was amplified using gene-specific primers 5' ACATCCGCTGGAAGGTGC 3' and 5' TCTG TATGGTAACATTGTGCTC 3 ' as forward and reverse primers respectively. PCR was performed on subtracted and unsubtracted secondary PCR products using the actin primers. The samples were analyzed after 18, 23, 28 and 33 cycles of PCR. All the PCR products were then subcloned into pGEM ${ }^{\circledR}$-T Easy Vector System (Promega Inc. Madison, USA) and transformed in JM109 cells to construct a subtracted cDNA library. DNA sequencing was carried out using the Big Dye Terminator kit (ABI Systems) using the sequencing primers T7 (5'CTAATACGACTCACTATA GGGC 3') and Sp6 (5' CATACGATTTAGGTGACACT ATA 3'). The sequence database similarity searches were done using BLAST programme of NCBI and the sequences were submitted in dbEST (GENBANK_ACCN EY458058-EY458062). Alignment of deduced amino acid sequences of Piper nigrum metallothionein type-2 to other type-2 metallothionein sequences was obtained using the program CLUSTALW. To determine the full length coding sequence of metallothionein homologue, 5'and 3' RACE was performed. The cDNA was synthesized following SMART RACE cDNA Amplification Kit protocol (Clontech, USA) and PCR amplified using the 5'and 3' RACE primers provided in the kit along with gene-specific primers (Forward 5' AAGCAGCACTTCACCGAGG 3' and Reverse 5' GGAGGAACATTTTTACACACG 3') for 3' and 5' RACE respectively. The RACE products were cloned into pGEM ${ }^{\circledR}-\mathrm{T}$ Easy Vector and sequenced.

The differential transcript abundance of metallothionein type-2 in leaf and root tissue was further quantified by Real-Time quantitative RT-PCR, using $\mathrm{SYBR}^{\circledR}$ Green PCR Master Mix kit (Applied Biosystems, Europe). The gene-specific primers (Forward 5' AAGCAGCACTTCA CCGAGG 3' and Reverse 5' GGAGGAACATTTTTACA CACG 3') designed using the Primer Premier software were used to amplify the target gene in Real-Time PCR analysis. A black pepper actin gene was used as an endogenous control in the RT-PCR reactions. Each reaction was carried out using $2 \mu \mathrm{L}$ of the cDNA preparation in a final reaction volume of $25 \mu \mathrm{L}$ following the manufacturer's protocol. Three replicate reactions of each tissue were maintained for the Real-Time PCR experiments. The endogenous actin gene was also analysed in triplicate. PCR was performed with two initial steps of $50^{\circ} \mathrm{C}$ for $2 \mathrm{~min}$ and $95^{\circ} \mathrm{C}$ for $10 \mathrm{~min}$, followed by 40 cycles of $95^{\circ} \mathrm{C}$ for $15 \mathrm{~s}$, $60{ }^{\circ} \mathrm{C}$ for $30 \mathrm{~s}$ and $60^{\circ} \mathrm{C}$ for $1 \mathrm{~min}$ with final extension at $72^{\circ} \mathrm{C}$ for $5 \mathrm{~min}$. To quantify abundance of metallothionein mRNA, the data is presented as a function of the abundance of the housekeeping gene $\beta$-actin. The threshold cycle $(\mathrm{Ct})$ was calculated by the 7500 Real Time PCR System (Applied Biosystems, Europe) software to indicate significant fluorescence signals rising above background during the early cycles of the exponential amplification phase. The dissociation curve of the amplified product was examined for each reaction to rule out the possibility of primer-dimers contributing to the amplification signal.

For Northern blotting, $20 \mu \mathrm{g}$ of total RNAs isolated from leaf, root and stem of Piper nigrum were separated on $1.5 \%(\mathrm{w} / \mathrm{v})$ agarose-formaldehyde denaturing gel, run in 1X MOPS buffer and blotted onto a nylon membrane (Hybond-N, Amersham) with $3 \mathrm{M} \mathrm{Nacl} / 0.01 \mathrm{~N} \mathrm{NaOH}$. After UV cross-linking, the membrane was hybridized with an $\alpha^{32} \mathrm{P}$ labeled probe in Church-Gilbert buffer ( $0.5 \mathrm{M}$ sodium phosphate buffer, $7 \%$ SDS, $0.01 \%$ BSA and $1 \mathrm{mM}$ EDTA at $65^{\circ} \mathrm{C}$ overnight). The probe was generated by restriction digestion of the $353 \mathrm{bp}$ metallothionein homologue obtained from the subtracted library and labeled by $\alpha^{32} \mathrm{P}$ $\mathrm{dCTP}$ incorporation following the probe labeling protocol (NewEngland Biolabs, USA). The membrane was washed with $1 \mathrm{X} \mathrm{SSC} / 0.1 \%$ SDS at room temperature and at $65^{\circ} \mathrm{C}$ for $10 \mathrm{~min}$ each, followed by a final wash with $0.5 \mathrm{X}$ $\mathrm{SSC} / 0.1 \% \mathrm{SDS}$ at $65^{\circ} \mathrm{C}$ for $10 \mathrm{~min}$ The image was then captured by exposing the membrane to Molecular Imager ${ }^{\circledR}$ FX (BioRad, USA).

The quality of RNA was checked by gel electrophoresis using $2 \%(\mathrm{w} / \mathrm{v})$ agarose gel stained with ethidium bromide. Absorbance was determined at wavelengths 260 and $280 \mathrm{~nm}$, which gave a ratio ranging from 1.8 to 2 , indicating good quality of RNA. The subtracted products on gel analysis appeared as a smear ranging in size from $400 \mathrm{bp}$ to $1.5 \mathrm{~kb}$, with a definite band at $500 \mathrm{bp}$ (Figure 1a, lane5). The experimental control subtraction product (Figure 1a, lane 3) yielded a pattern identical to ØX174/HaeIII digest (Figure 1a, lane 1), which was identical to the control subtraction provided in the kit (Figure 1a, lane 2), confirming that the experimental control subtraction has worked. The efficiency of experimental subtraction procedure using leaf as tester and root as driver was assessed by comparing the relative abundance of the constitutively expressed gene actin before and after subtraction (Figure 1b). PCR amplification of actin revealed that the band corresponding to actin appeared after 28cycles in the unsubtracted sample (Figure $1 \mathrm{~b}$, lane 8 ) while in the subtracted sample, the amplification product was visible after 33 cycles (Figure 1b, lane 5). 
Seventy-five subtracted clones were obtained and all were sequenced. The clones showed varying degrees of homologies to Alanine aminotransferase (17\%), Cinnamoyl CoA reductase $(10 \%)$, Leaf peroxidase $(4 \%)$, Germacrene D-synthase (11\%), Photosystem II (6\%), SOD chloroplast precursor $(3 \%)$, and proteins of unknown function (19\%). One of the subtracted clones (PNMS5), which yielded a 353 bp fragment, showed $30 \%$ redundancy. Sequence analysis of the fragment exhibited $93 \%$ identity to Citrullus lanatus CLMT2 mRNA for metallothionein type-2 at the nucleotide level. Translated query of the same demonstrated $85 \%$ identity to Malus $x$ domestica metallothionein-like protein mRNA and 62\% identity to Salix matsudana (metallothionein type-2) mRNA. RACE analysis of metallothionein type- 2 revealed a full length coding sequence of 408 bp length (GENBANK_ACCN

(a)

(b)
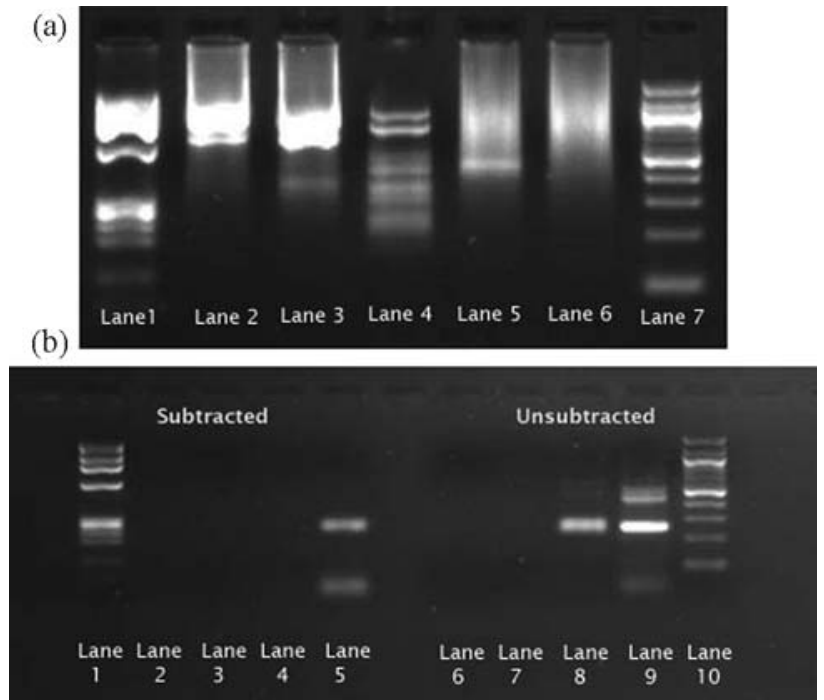

Figure 1 - (a) Secondary PCR products after subtraction. Lane 1 ØX174/HaeIII digested marker; lane 2 - Control subtracted sample from kit; lane 3 - Experimental subtracted control cDNA; lane 4 - Experimental unsubtracted control; lane 5- Experimental subtracted sample; lane 6 - Experimental unsubtracted sample; lane 7-100 bp ladder; (b) PCR analysis of subtraction efficiency using actin primers. PCR was performed on subtracted and unsubtracted samples using equal quantity (50 ng) of cDNA from each sample. Lane 1 - ØX174/HaeIII digested marker; lanes 2 and 6-18 cycles; lane 3 and 7-23 cycles; lanes 4 and 8-28 cycles; lanes 5 and 9-33 cycles; lane $10-100$ bp marker.
EY458058). The identity of the RACE product was confirmed by sequencing. The deduced amino acid sequence contains Cys- rich regions typical of plant type-2 metallothioneins, including the presence of a CXC motif at the carboxyl terminus. The alignment of deduced protein to other eight plant type -2 metallothioneins is reported in Figure 2.

The relative abundance of metallothionein transcripts in leaves was further quantified by 7500 Real time PCR system analysis (Applied Biosystems, Europe) using the SDS 3.1 software (Table 1). The Ct values in Table-1 depict the average $\mathrm{Ct}$ of triplicates for each tissue. A comparison of the transcript level of metallothionein type-2 homologues in leaf, root and stem tissues was carried out using Northern blotting. The total RNA used for Northern analysis using the partial metallothionein fragment as the probe showed a high expression of metallothionein gene in leaves when compared to root and stem (Figure 3a) which did not show detectable level of transcript accumulation. Equal intensities of 18SrRNA from the tissue samples served as loading control (Figure 3b).

SSH technique has been efficiently used for identification of many differentially expressed plant genes (Chou et al., 2006) and for generation of equalized and enriched tissue-specific cDNA library (Stahl et al., 2004). One of the advantages of using $\mathrm{SSH}$ is the normalization step in-

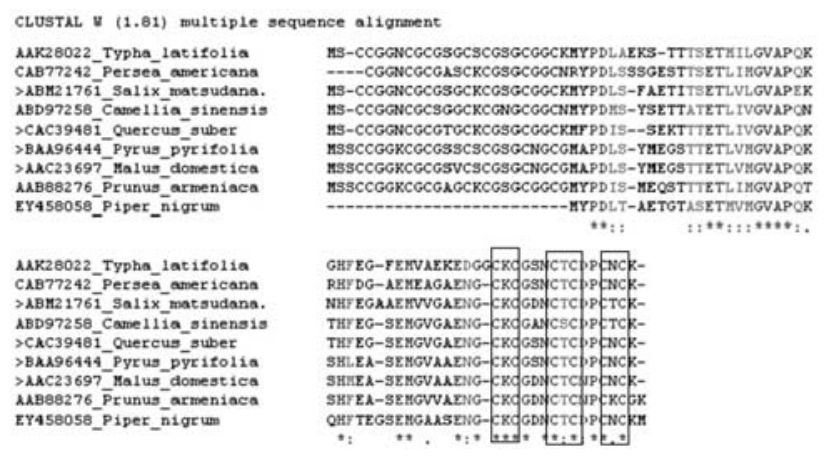

Figure 2 - Multiple Sequence Alignment. Sequence alignment of metallothionein type-2 of Piper nigrum to type-2 metallothioneins from other plant sources. Sequences were aligned by the CLUSTALW program. Conserved CXC amino acids in the 3' domain are shown.

Table 1 - Real-Time RT-PCR analysis of metallothionein type-2 transcript. Relative quantification study was done to calculate the fold expression of metallothionein in root and leaf. Analysis was performed with cDNAs from root $(\mathrm{avgCt}=23.592)$ and leaf $(\operatorname{avgCt}=16.649)$. Metallothionein transcript levels are normalized to $\beta$-actin levels using the formula $\mathrm{dC}_{\mathrm{T}}=\mathrm{C}_{\mathrm{T}}$ (metallothionein) $-\mathrm{C}_{\mathrm{T}}$ (actin) where avgCt of actin in root and leaf is $\left(\mathrm{C}_{\mathrm{T}}=21.570\right)$ and $\left(\mathrm{C}_{\mathrm{T}}=21.657\right)$ respectively.

\begin{tabular}{lcccccrr}
\hline Sample & Detector & Task & $\mathrm{AvgCt}^{\mathrm{a}}$ & $\operatorname{AvgdCt}^{\mathrm{b}}$ & $\mathrm{dCt}$ std error & $\mathrm{ddCt}^{\mathrm{c}}$ & $\mathrm{RQ}^{\mathrm{d}}$ \\
\hline Root (calibrator) & ME & Target & 23.592 & 2.023 & 0.075 & 0.000 & 1.000 \\
Leaf & ME & Target & 16.649 & -5.009 & 0.050 & -7.031 & $* 130.816$ \\
\hline
\end{tabular}

${ }^{a} \mathrm{Avg} \mathrm{Ct}$ indicates the average of the $\mathrm{C}_{\mathrm{T}}$ values (threshold cycles) obtained for three triplicates.

${ }^{\mathrm{b}} \mathrm{AvgdCt}$ is determined by subtracting the average actin $\mathrm{C}_{\mathrm{T}}$ value from the average metallothionein $\mathrm{C}_{\mathrm{T}}$ value.

${ }^{\mathrm{c}}$ The calculation of ddCt involves subtracting dCt calibrator value (root) from the dCt target value (leaf).

$\mathrm{d} *$ Relative quantification is given as the fold expression change given by the equation $2^{\text {-ddCt }}$. 

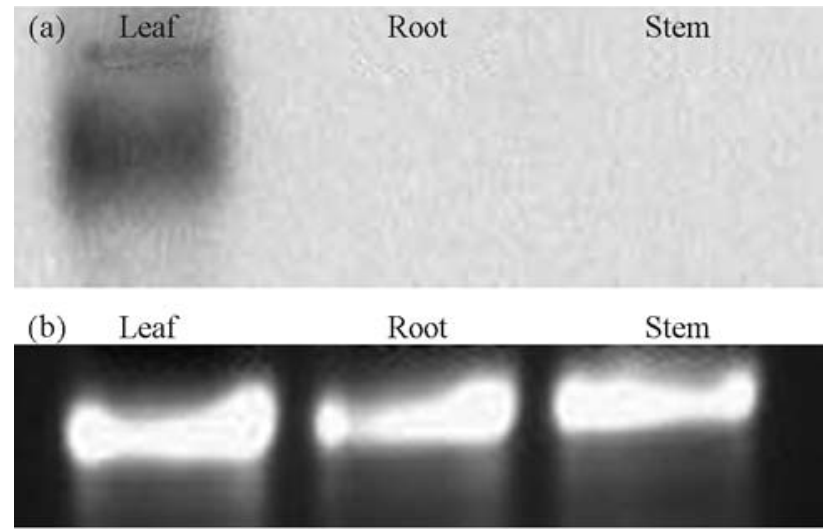

Figure 3 - (a) Northern blot analysis. Equal amount $(20 \mu \mathrm{g})$ of RNA from leaf, root and stem tissue was loaded and the membrane was probed with $\alpha^{32} \mathrm{P}$ labelled metallothionein type-2 homologue from P. nigrum. (b) 18 SrRNA control. The equal intensity of 18 SrRNA from all the three tissues serves as loading control.

volved, which is highly efficient in removing the transcripts common to driver and tester population, allowing the enrichment of differentially expressed cDNA in the subtracted population (Diatchenko et al., 1996). In the present study, PCR amplification of constitutively expressed gene actin occurred after cycle 28 in the unsubtracted sample, whereas in the subtracted sample enriched for differentially expressed transcripts, an amplification product was visible only after 33 cycles. This result indicates the successful subtraction of actin and hence establishes the efficiency of the subtraction procedure. Among the subtracted clones, predominance of metallothionein type- 2 homologues in the population could reflect it's overexpression in the tester (leaf) population, as those genes that are highly differentially expressed, will appear in the library a large number of times. Real Time PCR data established that the transcript level of metallothionein type-2 in leaf is 130 fold higher than in the root and the Northern blot analysis confirmed the metallothionein transcript upregulation in leaf compared to stem.

Typically, plant metallothioneins are Cys-rich proteins and further categories as types 1 and 2 have been designated on the basis of predicted location of Cys residue (Scott and Albert, 2005). Metallothionein type-2 transcripts have been detected primarily in mature leaves. The high levels of expression of metallothionein type- 2 in leaves, especially in trichomes is correlated to the secretory function of trichomes to exude excess heavy metals accumulating preferentially in leaves (Garcia-Hernandez et al., 1998) and moreover, leaf trichomes produce secretions that are thought to provide a first line of defence against pests and pathogens (Wang et al., 2002). A comparative study on accumulation of $\mathrm{Cd}, \mathrm{Fe}, \mathrm{Cu}, \mathrm{Mn}$ and $\mathrm{Zn}$ in commonly used tropical spices indicated a highest concentration of these metals in the leaves and seeds of Piper nigrum (Ozkuthu et al., 2006). Through our preliminary results, SSH has demonstrated its efficiency and we will now use it to further characterize a set of tissue specific genes and promoters for genetic improvement of black pepper.

\section{Acknowledgments}

We gratefully acknowledge the financial support received from the Kerala Biotechnology Commission, Kerala State Council for Science, Technology and Environment (KSCSTE) for carrying out this research work. S.M.A is grateful to KSCSTE for the award of JRF.

\section{References}

Chou MX, Wei XY, Chen DS and Zhou JC (2006) Thirteen nodule- specific or nodule-enhanced genes encoding products homologous to cystein cluster proteins or plant lipid transfer proteins are identified in Astragalus sinicus L. by suppressive subtractive hybridization. J Exp Bot 57:2673-85.

Diatchenko L, Lau YC, Campbell AP, Chenchik A, Moqadam F, Huang B, Lukyanov S, Lukyanov K, Gurskaya N, Sverdlov ED, et al. (1996) Suppression subtractive hybridization: A method for generating differentially regulated or tissuespecific cDNA probes and libraries. Proc Natl Acad Sci USA 93:6025-6030.

Dicto J and Manjula S (2005) Identification of elicitor-induced PR5 gene homologue in Piper colubrinum link by suppression subtractive hybridization. Curr Sci 88:624-627.

Garcia-Hernandez M, Murphy A and Taiz L (1998) Metallothioneins 1 and 2 have distinct but overlapping expression patterns in Arabidopsis. Plant Physiol 118:387-397.

Nair RR and Gupta DS (2006) High frequency plant regeneration through cyclic secondary somatic embryogenesis in black pepper (Piper nigrum L.). Plant Cell Rep 24:699-707.

Ozkuthu F, Sekeroglu N and Kara SM (2006) Monitoring of cadmium and micronutrients in spices commonly consumed in Turkey. Res J Agric \& Biol Sci 2:223-226.

Scott D and Albert LL (2005) Maize metallothionein promoter. Patent Publication n. WO/2005/063997.

Song P, Heinen JL, Burns TH and Allen RD (2000) Expression of two tissue specific promoters in transgenic cotton plants. J Cotton Sci 4:217-223.

Stahl DJ, Kloos DU and Hehl R (2004) A sugar beet chl a/b binding protein promoter void of G-box like elements confers strong and leaf specific reporter gene expression in transgenic sugar beet. BMC Biotechnol 5:31.

Wang W, Gan S and Wagner GJ (2002) Isolation and characterization of the CYP71D16 trichome-specific promoter from Nicotiana tabacum L. J Exp Bot 53:1891-1897.

\section{Internet Resources}

BLAST /NCBI, www.ncbi.nlm.nih.gov/BLAST/

CLUSTALW, http://workbench.sdsc.edu.

$$
\text { Associate Editor: Márcio de Castro Silva Filho }
$$

License information: This is an open-access article distributed under the terms of the Creative Commons Attribution License, which permits unrestricted use, distribution, and reproduction in any medium, provided the original work is properly cited. 